\title{
EDITORIAL
}

\section{The effect of not using an internal mammary artery as a conduit for coronary artery bypass grafting}

\author{
B J Leavitt
}

Heart 2004;90:1377-1378. doi: 10.1136/hrt.2003.027383

When presented with a high risk case for coronary bypass surgery, the surgeon can confidently use an internal mammary artery as a conduit for that patient

$\mathrm{T}$ he use of the internal mammary artery has clearly been one of the most beneficial innovations in the history of the surgical treatment of coronary artery disease. Since Green's introduction of the internal mammary artery (IMA) as a conduit for coronary artery bypass graft (CABG) surgery in 1970, ${ }^{1}$ there has been a significant number of studies looking at the effects of this artery that lies under the surface of the chest wall. There is no other clearly documented use of this artery other than for coronary artery bypass surgery. Its proximity to the heart, coupled with its size and native inflow, make it an ideal candidate to serve as a conduit for diseased coronary arteries.

After Green's introduction of the IMA as a conduit for CABG surgery, most of the studies focused on the long term patency of the IMA and survival. Other studies looked at the postoperative complications associated with the use and the harvesting of the IMA. Bilateral IMA usage was also studied in a similar fashion.

\section{SURGERY DATABASES}

There have been several large cooperative databases in cardiac surgery that have studied both the short- and long-term effects of the use of the IMA as a conduit for CABG compared to saphenous vein graft (SVG) conduits alone. In 1986 Loop clearly showed improved 10 year survival in those patients who received an IMA graft. $^{2}$ After multivariate analysis, at 10 years patients who received SVG only had 1.6 times the risk of death compared to patients who had an IMA graft. Ten years later Cameron reported the coronary artery surgery study (CASS) results on 15 year survival in those patients who received an IMA graft. ${ }^{3}$ There was a $27 \%$ reduction in survival in patients who received an IMA graft compared to patients receiving SVG alone. He noted that the survival benefit of an IMA graft was present in all subgroups of patients undergoing CABG. It was seen in men and women, younger as well as older, well preserved and impaired ventricular function, and patients with significant left main coronary artery disease (CAD). Cameron ended his manuscript with a powerful sentence that stands the test of time for cardiac surgery: "The ITA graft is a powerful surgical tool and should not be withheld from any subgroup of patients".

In 1995 Cameron and Green looked at 20 year follow up of patients who received an IMA or vein grafts alone. The presence of an IMA graft at 20 years resulted in a survival of 4.4 years greater than patients who received vein grafts only. The use of an IMA was associated with fewer reoperations, fewer myocardial infarctions, and less early recurrence of angina. ${ }^{4}$

\section{SINGLE AND BILATERAL IMA GRAFTS}

There have been several studies looking at the operative risks of using both single and bilateral IMA grafts at the time of CABG surgery. In 1985 Cosgrove was first to show that using SVG alone increased the operative risk. ${ }^{5}$ Early operative experience with the IMA as a conduit for CABG showed that the IMA was used less often in women, elderly patients, non-elective surgery, and patients with ejection fractions $<50 \%$. ${ }^{6}$ Despite the difference in patterns of use, patients who received an IMA in all risk categories benefited in operative mortality. In 1991 Morris reported that diabetics receive an IMA graft less often than non-diabetics. Five year survival was significantly improved when an IMA graft was used, even in the diabetic population. ${ }^{7}$

Grover looked at 14172 patients who underwent CABG surgery in the Veterans Affairs hospital system. The presence of an IMA graft demonstrated a reduction in operative mortality. The reduction was present in all risk quartiles. He also showed that there was not a higher complication rate associated with single IMA use. However, bilateral IMA use was associated with an increase in mediastinitis. ${ }^{8}$

Loop in 1990 showed there was an increased risk of sternal complications in diabetic patients who had bilateral ITA grafts. However, bilateral ITA grafts in non-diabetic patients had no increase in sternal complications. ${ }^{9}$

\section{ELDERLY CABG PATIENTS}

The average age of patients who are undergoing CABG continues to rise. Therefore, careful study of elderly patients who receive an IMA during CABG surgery is a timely issue. In a small study published in 1990, Gardner showed that early

Abbreviations: $C A B G$, coronary artery bypass graft; $C A D$, coronary artery disease; CASS, coronary artery surgery study; IMA, internal mammary artery; ITA, internal thoracic artery; NNE, Northern New England Cardiovascular Disease Study Group; NQF, National Quality Forum; SVG, saphenous vein graft 
and four year survival were improved when an IMA was used as a conduit for CABG. ${ }^{10}$

The Northern New England Cardiovascular Disease Study Group (NNE) is a voluntary research consortium composed of clinicians, scientists, and hospital administrators. We have been collecting preoperative, operative, and postoperative data on patients undergoing CABG surgery since 1986. Currently over 62000 patients have had their CABG surgery in Maine, New Hampshire, and Vermont, as well as several hospitals in Massachusetts. The overall intent of the NNE is to foster continuous quality improvement in the cardiovascular care given to our patients by pooling our process and outcome data in combination with feedback to our practitioners. ${ }^{11}$ In addition, we have linked our database to the National Death Index in order to study the long term effects of CABG surgery on these patients. We have had a keen interest in the use of the IMA as a conduit for CABG surgery. In 1997 the NNE reported our patterns of use of the IMA in our region. We looked at nearly 8000 patients who underwent CABG surgery between 1992 and 1995. The individual surgeon IMA usage ranged from 42-95\%. Women and older patients received an IMA less often. Emergent and elective operations were associated with a lower IMA use. However, it was noted that the use of the IMA in these patients increased during the study interval, presumably because of interval feedback of the data to the surgeons. ${ }^{12}$

\section{IN-HOSPITAL MORTALITY}

Because our study noted a wide use pattern of the IMA in our region, the NNE next looked at the in-hospital mortality and other short term outcomes of the IMA and CABG surgery. This study was a retrospective review of our CABG surgical experience in 21273 patients from 1992 through 1999. The adjusted odds ratio for in-hospital mortality in our study was 0.40. The odds ratios for in-hospital death showed a significant benefit in all subgroups of patients except the elective group $(p=0.06)$. The rates of stroke, return to cardiopulmonary bypass, return to the operating room for bleeding, and mediastinitis were less in the IMA group, although not significantly so. It was very clear that the use of the IMA in CABG surgery was protective in all groups, including the high risk groups that previously had lower rates of IMA use. ${ }^{6}{ }^{12}$

Recently, medical administrators and health care practitioners have critically looked at improving the quality of care delivered to all patients. Since cardiovascular disease affects many patients cared for in health care institutions, there has been a focus on this group of patients who utilise a significant amount of health care resources. The National Quality Forum (NQF) was established in 1999 to foster widespread quality improvement in health care. The Centers for Medicare and Medicaid Services and the Agency for Healthcare Research and Quality asked the NQF to identify voluntary consensus standards for hospital performance. The NQF initiated 39 consensus standards in eight condition specific areas. In CABG surgery the utilisation of an IMA conduit was determined to be a voluntary standard for hospital care. Therefore, hospitals and/or surgeons who utilise the IMA less during CABG surgery are not providing a current standard of care in cardiac surgery. Health care consumers can now select high quality care. This in turn will provide overall improvement in the quality of the care delivered. ${ }^{13}$

Therefore, when a surgeon is presented with a high risk case for CABG surgery, that surgeon can confidently use an IMA as a conduit for that patient. Not to do so would be subjecting that patient to increased hospital mortality, increased risk of a future myocardial infarction, increased risk of re-operation, and decreased long term survival.

\section{REFERENCES}

1 Green GE, Stertzer SH, Gordon RG, et al. Anastomosis of the internal mammary artery to the distal left anterior descending coronary artery. Circulation 1970:41:11-79-84.

2 Loop FD, Lytle BW, Cosgrove DM, et al. Influence of the internal-mammaryartery graft on 10-year survival and other cardiac events. N Engl J Med 1986;314:1-6.

3 Cameron A, Davis KB, Green G, et al. Coronary bypass surgery with internalthoracic-artery grafts - effects on survival over a 15-year period. N Engl J Med 1996;334:216-9

4 Cameron A, Green G, Brogno DA, et al. Internal thoracic artery grafts: 20year clinical follow-up. J Am Coll Cardiol 1995;25:188-92.

5 Cosgrove DM, Loop FD, Lytle BW, et al. Does mammary artery grafting increase surgical risk? Circulation 1985;72(suppl 2):170-4.

6 Edwards FH, Clark RE, Schwartz M. Impact of internal mammary artery conduits on operative mortality in coronary revascularization. Ann Thorac Surg 1994;57:27-32.

7 Morris JJ, Smith LR, Jones RH, et al. Influence of diabetes and mammary artery grafting on survival after coronary bypass. Circulation $1991 ; 84$ (suppl III):III-275-84.

8 Grover FL, Johnson RR, Marshall G, et al. Impact of mammary grafts on coronary bypass operative mortality and morbidity. Ann Thorac Surg 1994,57:559-69.

9 Loop FD, Lytle BW, Cosgrove DM, et al. J. Maxwell Chamberlain memorial paper. Sternal wound complications after isolated coronary artery bypass grafting: early and late mortality, morbidity, and cost of care. Ann Thorac Surg 1990;49:179-86.

10 Gardner TJ, Greene PS, Rykiel MF, et al. Routine use of the left internal mammary artery graft in the elderly. Ann Thorac Surg 1990;49:188-94.

11 O'Connor GT, Plume SK, Olmstead EM, et al. A regional intervention to improve the hospital mortality associated with coronary artery bypass graft surgery. The Northern New England Cardiovascular Disease Study Group. JAMA 1996;275:841-6.

12 Leavitt BJ, Olmstead EM, Plume SK, et al. Use of the internal mammary artery graft in northern New England. Circulation 1997;96(suppl II):II-32-37.

13 The National Quality Forum. National voluntary consensus standards for hospital care: an initial performance measure set. Washington DC: The National Quality Forum, 2003. 